\title{
Disaster Resilience in a Hakka Community in Taiwan
}

\author{
Li-ju Jang \\ Department of Medical Sociology and Social Work, Chung Shan Medical University, Taiwan \\ Jieh-jiuh Wang \\ Department of Architecture, Graduate School of Architecture and Urban Disaster Management, Ming Chuan University, Taiwan
}

\begin{abstract}
Survivors of the 921 Earthquake in the Tung Shih areas were the target population for this study. The Sresearchers used purposive sampling strategies to select information-rich participants for study in depth. A total of 15 interviewees and 8 focus group members participated in this study. Qualitative data analysis software, ATLAS.ti 5.5, was used for cross-case and content analyses. The results indicate that acceptance, preparedness, self-reliance, spirituality, Hakka spirit, resource availability, social support networks, and serving others have positive impacts on disaster resilience. Participants from the in-depth interviews group affirm the importance of government involvement. Participants from the focus group pay special attentions on re-establishing social support networks. Furthermore, they reinforce the importance of understanding culture and meanings for the local people.
\end{abstract}

Keywords: acceptance, disaster resilience, preparedness, social support networks, spirituality

There has been a tendency for natural disasters to become more severe and to occur more frequently because of changes in people' relationship with the natural resource environment. In Taiwan, the Ministry of the Interior (MOI, 2008) reported that 270 natural disasters, including 196 typhoons, 49 floods, 22 damaging earthquakes, and three other disasters occurred on the island from 1958 to 2007. More than 32,944 people died or were injured. From 1998 to 2007, 54 typhoons reached Taiwan. Chou (2009) reports that about $72 \%$ of natural disaster damage was caused by typhoon. The frequency of earthquake occurrence reached the peak in 1999 and 2000, during which there were more than 4,000 earthquakes. However, none of these earthquakes packed a more lethal force than the 921 and 1022 Earthquakes. Of all the deaths and injuries caused by natural disasters, about $48 \%$ were victims of earthquakes (Lin, 2002). Loss of lives and property damage from earthquakes are thus major concerns in Taiwan.

Given existing levels of societal development in areas susceptible to earthquakes, identifying what can be done to increase people's resilience has emerged as an important facet of risk management. In the past, the focus of disaster studies has tended to be on the relationships between disasters, posttraumatic stress disorder (PTSD), and other pathological reactions (e.g., Norris et al., 2001). In recent years, researchers argue that disasters could produce positive results, and even foster posttraumatic growth (Cadell et al., 2003). This study explored factors influencing disaster resilience in a Hakka community at Tung Shih, Taiwan. In this article, disaster resilience is defined as the ability to (a) maintain or regain pre-disaster levels of functioning, (b) manifest successful adaptation, and/or (c) foster posttraumatic growth (Paton et al., 2003).

In Taiwan, Hakka people comprise about $15-20 \%$ of the population and are descended largely from Guangdong, China. They form the second-largest ethnic group on the island. Many of the Hakka people live in the hills or remote mountains. Their well-known qualities include frugality, diligence, self-reliance, and persistence (Yang, 2004). Norman Garmezy claims that researchers cannot talk about resilience in the absence of stress (as cited in Rolf, 1999). In this study, the 921 Earthquake (also known as the Chi-chi Earthquake) was used as a major stressor for evaluating disaster resilience in survivors in Tung Shih, Taiwan.

On September 21, 1999, a devastating earthquake, which Taiwanese people refer to as the 921 Earthquake, with a magnitude of 7.6 on the Richter scale, struck central Taiwan. The official report from MOI (Disaster Response Report, 2008) indicates that the catastrophe was responsible for 2,415 deaths, 29 people missing, 11,306 injuries, and making more than 110,000 people 
homeless. Of all affected counties and cities, Taichung County suffered the highest death toll, with 1,194 (or $49 \%)$. At the township level, Tung Shih (Figure 1) suffered the highest death toll with 358 (Liao, 1999; social aid, n.d.).

The researchers collected qualitative data through indepth interviews and focus groups. The emerged themes in cross-case analyses indicate that acceptance, experience of natural disasters, Hakka spirit, post-disaster life events, preparedness, resource availability, self-reliance, serving others, social support networks, and spirituality are factors influencing disaster resilience.

From past experience, the researchers found that the focus of disaster mitigation plans in Taiwan have focused on strengthening infrastructures. Most of the available resources were deployed to minimise the vulnerability of infrastructures. Yet, these plans have tended to overlook issues related to human vulnerability and the potential implication of disaster resilience for reducing injury and death. Mitchell (1990) remarks that the International Decade for Natural Disaster Reduction (IDNDR) tends to ignore the influence of human dimension. The risk to socially disadvantaged members of society not only derives from the greater likelihood of their living in hazard prone areas, but also from the fact that they are marginalised, or living in a state of long-term abnormality. The marginalisation is the result of a series

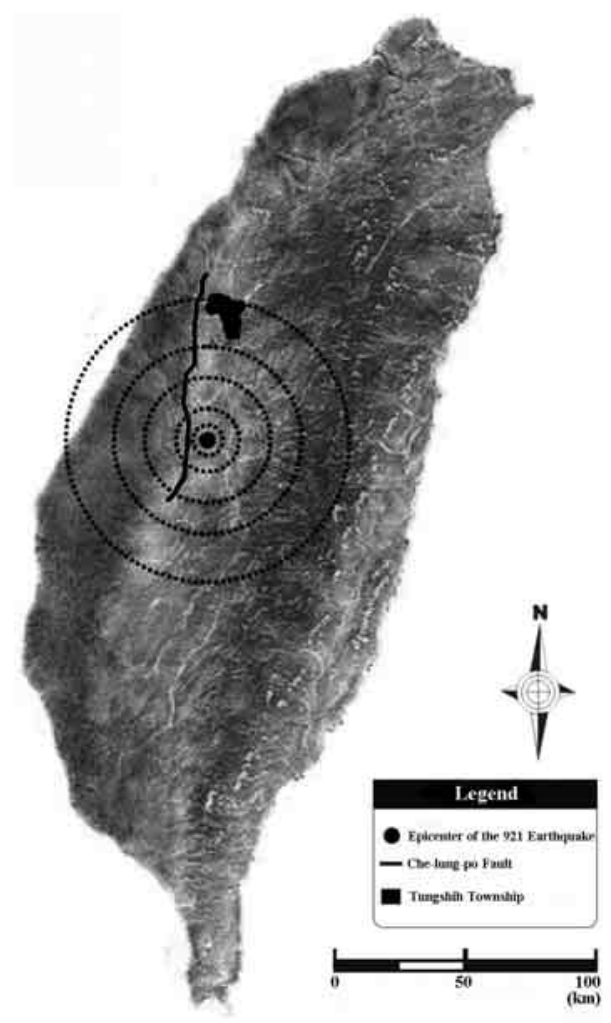

Figure 1

The location of the 921 earthquake of factors, including the social stratum, gender, age, race, and disability (Wisner, 1993). These factors have profound influence on people's possession and domination of power; for example, on people's ability to manage basic needs and rights. In order to better understand the human response to disasters, individually as well as collectively, the US government funded a series of studies (Mileti, 1996). The social-environmental approach emphasises the importance of taking adaptability, adjustability and lessons learned from the communities into consideration when coping with disasters (Mileti, 1999).

Cardona (2003) asserts that the vulnerability initiates in physical frangibility or exposure, socio-economic frangibility and lack of resilience. Liverman (1989) points out that many related terms are in fact used to establish similar concepts, such as vulnerability, fragility, resilience, risk, susceptibility, and adaptability. From the viewpoint of emergency management, vulnerability or fragility reflects the process of dynamics, development and accumulation of social and economic status corresponding to disasters (Lewis, 1999), while resilience represents the establishment of abilities and spiritual transformation that correspond to vulnerability in a social and economic status. Vulnerability is often considered the core of negative concepts, whereas resilience is of the positive. Both concepts are associated with social power, customs, and cultural values that express themselves through and between persons, as well as in the quality of relationships with the environment. Therefore, both vulnerability and resilience incorporate environmental, social and cultural factors, and provide the theoretical structure for the diverse characteristics of a disaster (Paton, 2006).

The direct link between disasters and pathological results is now being questioned. Paton and Johnston (2001) assert that the paradigm of disaster study is gradually being transformed from casualty and loss to community resilience or posttraumatic growth. Paton et al. (2003) even claims, 'We can learn and even prosper from exposure to adversity' (p. 205). Bankoff (2004) and Jang (2008) found that because of repetitive exposure to disasters, people in disaster-prone areas gradually develop effective coping strategies. Their disaster-coping related knowledge and experience provide valuable lessons for people under similar conditions. Hence, some disaster researchers continue exploring factors promoting disaster resilience and posttraumatic growth (Linley \& Joseph, 2004; Paton \& Johnston, 2001).

Disaster resilience comes with years of experience and training. Study findings suggest that culture plays an essential role in enhancing disaster resilience and coping style (Jang \& LaMendola, 2006, 2007; Rabin, 2005). Rabin emphasises that understanding local culture is the key to success in the process of relief work. Thus, for those who participate in disaster management should 
have comprehensive knowledge of the local cultures and community members' perceptions of disaster management. Emergency managers should evaluate and recognise the unique needs of individuals. Additionally, emergency managers have to plan and coordinate the disaster management works wisely. Local governments have the administrative authority, so they are the perfect liaisons for community resource linkages. Granot (1995) also points out if service providers can improve their ability for quick assessment of the self-sustainability of affected communities, they would be able to make proper decisions on deploying rescue and relief works in no time. It is also important to recognise the everyday or mainstream community and cultural competencies and characteristics can exercise an important influence on people's ability to cope with, adapt to and recover from disaster impacts (Paton \& Jang, in press).

The impacts caused by the same disaster can be dramatically different in various areas or even in the same area amongst different groups. In order to evaluate and respond to disaster more effectively, emergency management plans should include community participation (Paton \& Jang, in press). Both governmental and private sectors agencies require knowledge of the factors motivating local people to participate in emergency management plans. Community members' disaster coping skills would be sharpened and disaster resilience would be increased, if emergency managers are able to incorporate this knowledge into practice.

\section{Methodology}

This study used triangulation to secure an in-depth understanding of factors influencing disaster resilience (Denzin \& Lincoln, 2000). The researchers applied in-depth interviews and focus groups to collect qualitative data.
Qualitative and disaster research fit together well because they share a common flexibility. Disaster challenges affected areas in unexpected ways and with unanticipated consequences. Qualitative research offers the opportunity to identify relevant questions and to probe in-depth (Phillips, 1997). Tedeschi and Calhoun (1995) suggest that an important step for further understanding of posttraumatic growth is to use extensive interviews with disaster survivors and people who are associated with the survivors. Furthermore, qualitative research works well within the Hakka cultural context because the Hakka people are relational and connections are very important to them. Through the assistance of two key informants, the researchers were able to build a relationship of trust with interviewees and focus group members.

\section{Sampling In-Depth Interviews}

The researchers applied a snowball sampling strategy for selecting 'information-rich' participants for study in depth. The snowball started with two local key informants who were interested in disaster preparedness, and the construction of disaster resistant community. These two key informants were asked to refer prospective participants for this study. The criteria were that prospective participants must be: (a) 20 years or older; (b) survivors of the 921 Earthquake, and (c) residents of Tung Shih. Subsequently, the researchers invited prospective participants to refer people who they knew met the above criteria and were willing to participate in this study. The researchers interviewed a total of 15 participants. In order to hear various voices, they purposively interviewed people from different social economic statuses. Participants included four males and 11 females. Their ages ranged from 35 to 75 at the time of interviews. Their levels of education were from elementary through college.

Table 1

Characteristics of the Participants in the In-Depth Interviews Group

\begin{tabular}{|c|c|c|c|c|c|}
\hline ID & Gender & Age & Background & Education & Occupation \\
\hline TW01 & $\mathrm{F}$ & $30 \mathrm{~s}$ & 3-generation under one roof & Junior college & Pre-school teacher \\
\hline TW02 & M & $40 \mathrm{~s}$ & Wife with mental health concerns, son in 3rd grade & Elementary & Blue-collar worker \\
\hline TW03 & $\mathrm{F}$ & $50 \mathrm{~s}$ & Part-time religious worker & College & Elementary school teacher \\
\hline TW04 & $\mathrm{F}$ & $40 \mathrm{~s}$ & Domestic violence survivor & Junior high & Housewife \\
\hline TW05 & $\mathrm{F}$ & $60 \mathrm{~s}$ & Volunteer & College & Retired teacher \\
\hline TW06 & M & $50 \mathrm{~s}$ & 4-dimentional religious worker & College & Retired teacher \\
\hline TW07 & $\mathrm{F}$ & $40 \mathrm{~s}$ & Volunteer & Junior college & Self-employed \\
\hline TW08 & $\mathrm{F}$ & $60 \mathrm{~s}$ & Survivor of the 921 EQ \& 7-2 Flood, Buddhist & Elementary & Housewife \\
\hline TW09 & M & $60 \mathrm{~s}$ & Survivor of the 921, widower & Elementary & Farmer \\
\hline TW10 & $\mathrm{F}$ & $40 \mathrm{~s}$ & Single mom, lost her husband to the 921 & Senior high & Seasonal worker \\
\hline TW11 & $\mathrm{F}$ & $50 \mathrm{~s}$ & Participated in the 921 relief work & Junior college & Nurse \\
\hline TW12 & $\mathrm{F}$ & $60 \mathrm{~s}$ & Volunteer & Junior college & Retired \\
\hline TW13 & $\mathrm{F}$ & $40 \mathrm{~s}$ & Hakka cultural preservation worker & College & Elementary school teacher \\
\hline TW14 & M & $70 \mathrm{~s}$ & Survivor of the 921, living alone, Buddhist & Elementary & Recycling \\
\hline TW15 & $\mathrm{F}$ & $40 \mathrm{~s}$ & Survivor of 921 , single mom & Junior high & Blue-collar worker \\
\hline
\end{tabular}


Participants were farmers, blue-collar workers, retired teachers, and so forth (see Table 1). The researchers found that it was difficult to recruit male participants because of masculine pride and occupation. Men tended not to share defeated or negative experiences with others. According to the Tung Shih Township Farmers Association (2008), about $40 \%$ of the residents were farmers. Searching through scholarly works (such as Norris, et al., 2001; Paton, et al., 2003), the researchers found that farmers hardly participated in disaster studies.

\section{Focus Groups}

The researchers used a purposive sampling strategy to select participants. The logic of purposive sampling is to select people with rich information to participate in the study (Patton, 1990). In addition to the above three criteria for selecting participants for in-depth interviews, an additional criterion for focus group membership was that the participant was also a member of the Community Guardian Angels. Most of the members of Community Guardian Angels are survivors of the 921 Earthquake. All the participants experienced great loss from the 921, losing family members, relatives, students, homes, and/or properties. Many of them became social service recipients shortly after the catastrophe. Now, they have transformed themselves into voluntary service providers, serving other survivors and/or people in need. Their services include home visits to the elderly, foreign spouses (new immigrants), school dropouts, and so forth. Obviously, those Community Guardian Angels not only have manifested successful adaptation, but also have achieved a certain level of posttraumatic growth. A total of eight participants attended the focus group including one retired teacher, one tailor, one housewife, two farmers, and three social service aides. Their ages were between 40 and 60 .

\section{Data Collection}

Question guides were designed to keep the interviews focused. For the in-depth interviews study, the following data were collected: (1) factors influencing disaster recovery, (2) disaster coping strategies, (3) the impact of repetitive exposure to natural disasters on coping strategies, (4) family disaster preparedness, (5) factors influencing disaster preparedness, and (6) suggestions to emergency managers. For the focus group, the following data were collected: (1) motivators for joining the Community Guardian Angel, (2) volunteer experience on serving the 921 survivors and/or people in need, and (3) factors influencing a transformation process of being a service receiver becoming a voluntary service provider.

With participants' permission, the researchers audiotaped all interviews and focus group sessions. During the interviews, participants were free to ask questions regarding this study. After-session contacts were made for the purposes of clarification and verification. Seven student workers and two research assistants were hired to help with transcriptions and proofreading. Hoping that the message that participants would like to convey would be heard correctly, and man-made mistakes could be minimised in the procedure of data process.

When working with Taiwanese or Hakka interviews, the researchers would test the student workers' language abilities to ensure that they were capable of undertaking the tasks. Additionally, to avoid redundancy, participants of in-depth interviews and focus group were selected from two different sets of people. All transcriptions were imported to qualitative data analysis software, ATLAS.ti 5.5 , for cross-case analyses.

\section{Ethical Considerations}

For confidentiality purposes, the researchers assigned each participant a numerical code with two prefixes: 'TW' for participants of the in-depth interviews, and 'FG' for participants of the focus group. In order to correctly refer to the participants when it was necessary, without revealing their identity, a table that recorded the assigned ID number of each participant was constructed. Because the Hakka people are cautious of signing names on official documents, participants were verbally informed about the purpose of this study and what their rights were.

\section{Lessons Learned}

Several themes emerged on the subject of factors influencing disaster resilience. In the in-depth interview part of the study, the results of cross-case analyses indicate that social support networks, spirituality, acceptance, preparedness, resource availability, self-reliance, Hakka spirit, and serving others have positive and direct impacts on disaster resilience. Experience of natural disaster and post-disaster life experience have direct but negative impacts on it. An essential source of social support networks comes from family support, which is closely associated with post-disaster life event. Post-disaster life event has direct but negative impacts on social support networks. Resource availability have positive and direct impacts on preparedness and self-reliance. Disaster education is part of preparedness, and it has positive and direct impacts on attitudes toward disasters. Self-reliance is an important trait of Hakka spirit, which has positive and direct impacts on participants' willingness of serving others. In terms of governmental agencies, participants believe that it plays a key role in preparedness and resource availability. For some reason, they are reluctant to say that it has direct impact on their disaster resilience (Figure 2).

In the focus group part of the study, the researchers found similar results, as indicated in Figure 3. However, participants from the focus group often expressed their gratitude to gods and people for their help in times of need. Being grateful helps them to focus on the positive 


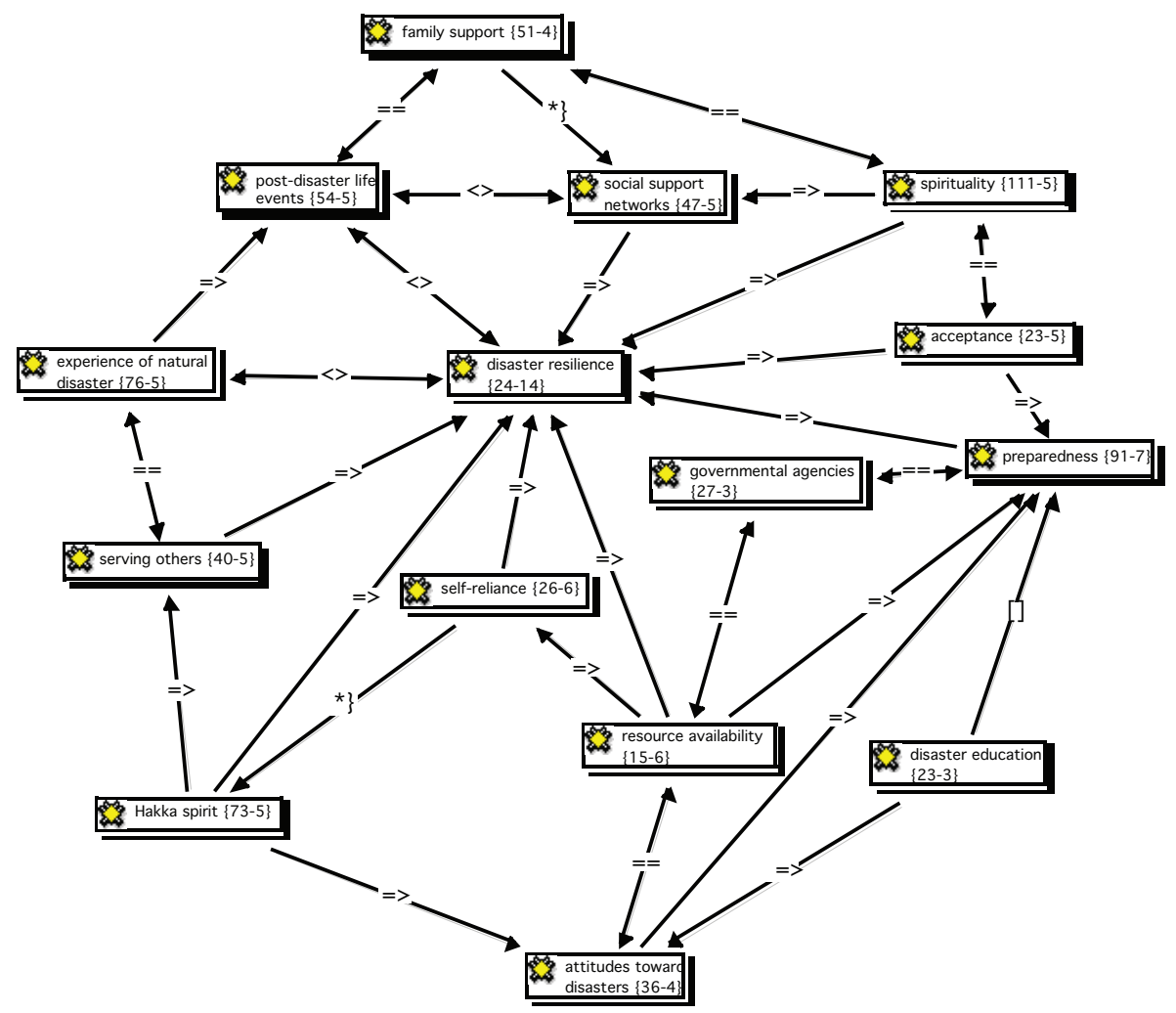

Figure 2

Themes emerged from the in-depth interviews group.

Note: $\geq$ is cause of $==$ is associated with, [] is part of, $\left.{ }^{*}\right\}$ is property of, $<>$ contradicts.

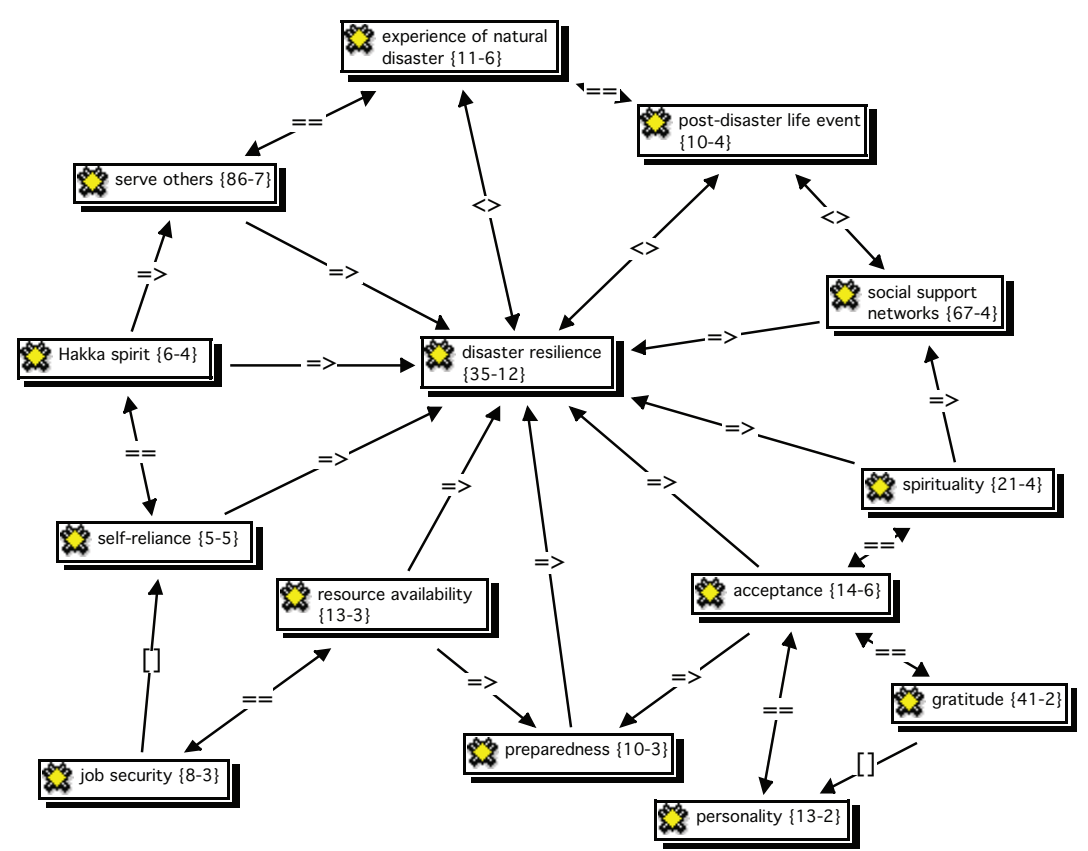

\section{Figure 3}

Themes emerged from the focus group.

Note: $\geq$ is cause of, $==$ is associated with, [] is part of, * $\}$ is property of, $<>$ contradicts. 
side of things. It also helps them to accept the established facts. Additionally, participants claimed that job security is essential to self-reliance and is associated with resource availability.

In this study, for those themes that have positive and direct impacts on disaster, resilience would be treated as a protective factor. In comparing the results in Figures 2 and 3 , the researchers found that at the personal-level, acceptance, preparedness, self-reliance and spirituality could be protective factors of disaster resilience. Hakka spirit, resource availability, social support networks, and serving others would be protective factors at the community-level (see Figure 4).

\section{Protective Factors at the Personal Level Acceptance}

Studies indicate that accepting disasters as part of life experience and desiring to live harmoniously with Nature have positive impacts on disaster resilience (Jang, 2008; Jang \& LaMendola, 2006). For those who accept an established fact, they understand that they have no power to change the fact, but are capable of coping with its effects. Consequently, they are more likely to apply problem-focused coping style, which has been identified as a factor increasing disaster resilience (Jameson, 2002; Paton \& Johnston, 2001), in times of crisis. Although survivors still suffer from sadness, somehow they are more likely to move forward, and not be stuck in the feelings of loss, or reliving the trauma. In this study, participants likened natural disasters to ordeals from Heaven. They stressed that no matter how hard the tests might be, life must go on. They encouraged the residents of hazard-prone areas to focus on the here-and-now. Learning to live with Natural harmoniously would be a promising way of coping with natural disaster. Participants indicated that because the established fact already happened, they decided on accepting fate.

\section{Preparedness}

Preparedness includes food storage, water and health care products, home safety, and so forth. In the present study, participants of the in-depth interviews group seemed to value disaster preparedness more than the focus group members. During the interviews, they often talked about the importance of disaster education and their personal disaster mitigation plans. Similarly, Rosenfeld et al. (2005) point out that disaster education is an essential part of community preparedness. It aims at increasing public awareness of what can happen and at enhancing readiness to act according to the proposed emergency operation plan.

However, some participants misunderstood that disaster preparedness meant to wrestle against Nature. After experiencing such a catastrophe, they learned to question the truthfulness of an old saying, 'Man's determination will always conquer the Nature'. Witnessing how destructive a disaster could be made them believe that disaster consequences were too catastrophic for personal action to make any difference to peoples' safety. Because they held this belief, they might be disinclined to act (Paton \& Jang, in press). Thus, the definition of 'preparedness' may need to be clarified. Hazards always exist. Being 'well-prepared'

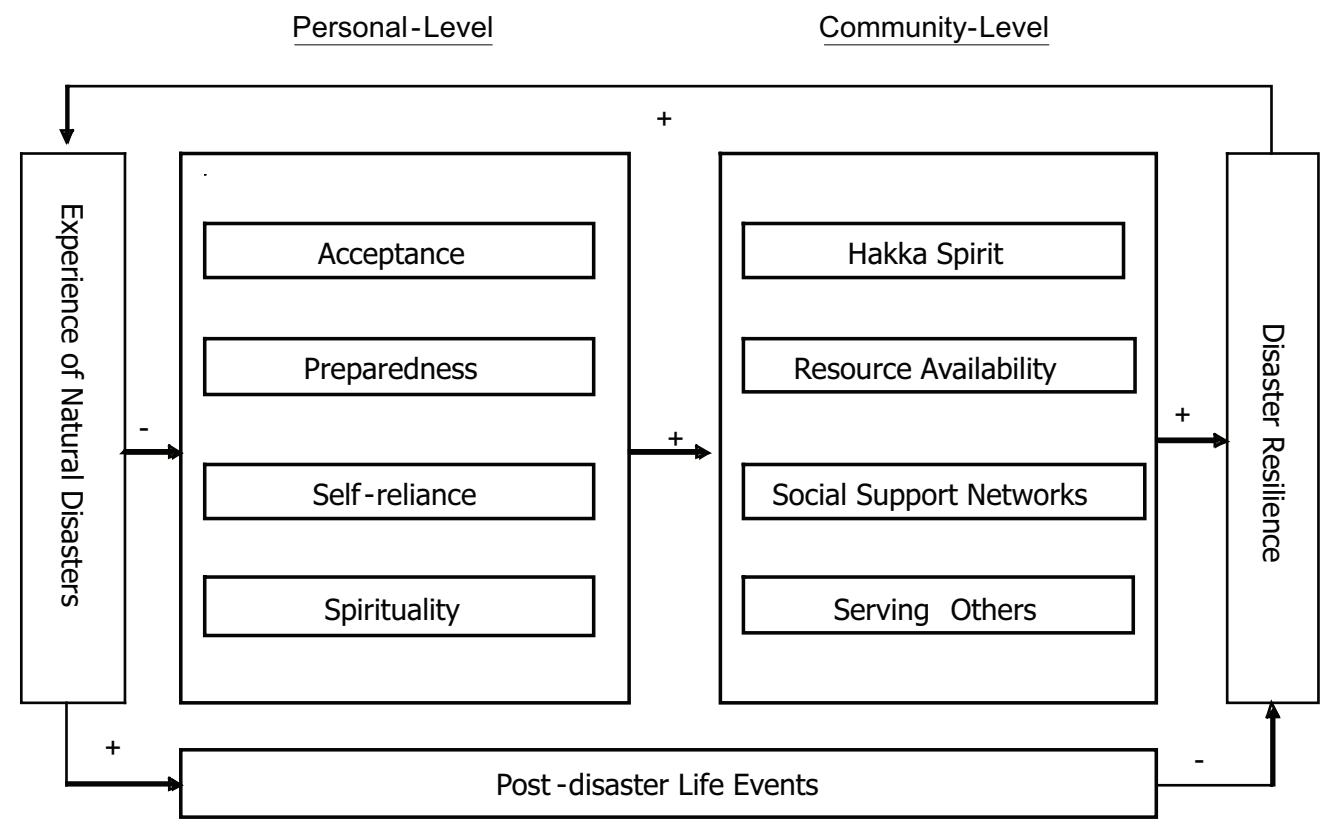

Note: + positive influence, - negative influence

Figure 4

Factors influencing disaster resilience. 
does not mean that hazard activity will not turn into disasters. However, preparedness can reduce likelihood of lives and property being lost. The goal of disaster mitigation and preparedness is not to wrestle against Nature, but to facilitate a capacity to co-exist with it and learn to live with Nature harmoniously (Paton, 2006B: Paton \& Jang, in press).

Additionally, most of the current emergency operations plans tend to focus on food storage, personal safety, evacuation routes and shelters, and building code reinforcement. In an agricultural township like Tung Shih, about $40 \%$ of residents are farmers. Minimising the crop losses may be their first priority when natural disasters attack. Thus, improving local transportation system may be involved in the emergency operation plan. Developing risk communication through joint ventures with local people, local government, Farmers Associations or other occupational associations, nonprofit organisations, and/or religious groups could increase the effectiveness of risk-management strategies.

In sum, Saleebey (2002) often emphasises the importance of 'strengths-based practice' that promotes people's resilience and growth. The role of disaster workers is not to do everything for survivors, but to empower them. In disaster preparedness, residents could be the leaders of local emergency operation plans. Residents are experts of their community concerns and coping mechanisms as well as their practical needs. Community members understand their priorities. Disaster experts may serve as technical assistants, information providers, as well as resources brokers.

\section{Self-Reliance}

Job security and good health conditions are essential to self-reliance. Job security ensures financial stability and reasonable living quality. Good health conditions provide strengths required to enjoy life, move forward, and face daily challenges. Compared to other factors, self-reliance is relatively less discussed. But similar ideas such as self-efficacy (Bandura, 1989) and perceived control of resource availability have been tested to show positive impacts on disaster resilience (Benight, et al., 1999; Norris, Byrne \& Diaz, 2001). In this study, participants recognised the importance of health on selfreliance. Besides good health, knowledge is another key element of self-reliance. Knowledge is power. Survivors need the required knowledge and information to quickly and calmly cope with crises. Participants pointed out that there was no free lunch. Survivors could not just sit and wait for assistance from the government or NGOs. No matter what happened, community members must rely on their own strengths to improve the conditions. Participants emphasised that being self-reliant made them feel happy and have a sense of achievement.

Although participants stressed the importance of selfreliance again and again, they did not deny the roles of the government in disaster management plans. Because the government has the power of administration, they can be the best coordinators among professionals, paraprofessionals, and volunteers in emergency operational plans, especially in a catastrophe that affects the entire community such as the 921 Earthquake (Jang, 2008).

\section{Spirituality}

Spirituality offers explanations of death, life, loss, and natural disasters. It brings comfort to participants. The impact of spirituality on disaster resilience cannot be overlooked. Nathanson (2003, p. 63) asserts that 'spirituality is an important force in recovery', because it helps the survivors identify inner strengths and find meaning in people's sufferings and behaviors (Cannon, 2008). In this study, participants indicated that with the support from religious belief, they have found ways to cope with challenges. They affirmed that religious belief helped them to be more optimism and see positive side of things. They also learned not to go to extremes. Likewise, Cadell et al. (2003, p. 280) emphasise that, '... One way individuals who face traumatic events attempt to find meaning is through religion or spirituality'. Cadell et al. conclude that the reconstruction of meaning is necessary because disasters often distort survivors' perception of self and the world, and provide some evidence that disaster resilience increases as spirituality grows. In a collectivist culture like Taiwan, where spirituality is also a way of life, the importance of shared meanings can be seen to be not only an interpretive tool, but also one that can possibly be useful as a prelude to the construction of interventions (Jang \& LaMendola, 2006).

Spirituality often guides norms and people's values. For example, Dove (2008) found that due to a particular religious belief in Mt Merapi, residents believe that volcano eruption is a positive change for the area. The Taiwanese people often use poe divination to denote gods' will (Jordan, n.d.). In Taiwan, religious groups have been the major sources of community services (religion, n.d.). Spirituality may strengthen residents' social support networks and enhance their sense of community. It even influences residents' level of acceptance on natural disasters. Studies show that those who are willing to face and accept the established fact of loss made by natural disasters are more likely to apply a problem-focused coping style to deal with their loss, and even solve problems (Jameson, 2002; Paton, 2000). In this study, participants believed that it was essential to understand the cycle of Nature. Participants claimed that religious beliefs encouraged people to work on personal merits and practice moral culture. People need to selfreflect when they experience natural disasters.

Likewise, Rabin (2005) stresses the importance of understanding culture in the helping process. Culturally competent practice and cultural sensitivity are goals for education for multicultural social work practice 
(Gutierrez, Zuniga \& Lum, 2004). This finding reinforces the importance of understanding culture and meanings to the local people.

\section{Protective Factors at the Community Level Hakka Spirit}

Most of the residents of Tung Shih are Hakkas. Hakka spirit is the essence of their culture, which consists of characteristics such as frugality, diligence, self-reliance, responsibilities, and persistence (Jang, 2008, Paton \& Jang, in press). The Hakka people even learn to accept disasters as part of life experience and live harmoniously with Nature. Normalisation and living with disasters are traits of disaster resilience. A sense of responsibility is one of the traits of Hakka spirit. It is also a key factor influencing coping style. Study results showed that participants who had a sense of responsibility toward their families and/or communities were more likely to apply a problem-focused coping style in times of crisis (e.g., TW10 \& TW15). Studies confirm that a problemfocused coping style may enhance disaster resilience (Karanci et al., 1999; Miller, Paton \& Johnston, 1999; Norris et al., 2001). Several participants believed that Hakka spirit was key factor that helped residents of Tung Shih to recover from the 921 Earthquake. Participant TW 01 asserted, 'Residents of Tung Shih possess the power of strong and determined will, they work hard without complaint. Their focus has been on rebuilding their homes'. Participant TW 07 confirmed that the Hakka people refuse to concede defeat. Participant FG 01 also claimed,

I rely on the strong determined will to pass through terrible ordeals. It's not easy. I lost most of my properties to the 921 . How can I fully recover from it? I would not be able to make it without strong determined will.

\section{Resource Availability}

Studies show that resource availability may promote disaster resilience. Generally speaking, resources consist of assistance from public as well as private sectors, such as financial aid, food aid, in-kind commodities, emergency necessities, social services, donations, humanitarian services, medical services, even services from volunteers (Bellavita, 2008; Carpenter, Hodge \& Pepe, 2008). Following a disaster, survivors often use available resources to solve problems. At this point, resource availability would improve their adaptation to new conditions and environment. In this study, the researchers found that resource availability has positive impact on self-reliance and would promote disaster resilience.

\section{Social Support Networks}

Disaster studies have found that social support networks have positive impact on disaster resilience or community resilience (e.g. Abramson et al., 2008; Wang, et al., 2000). Nelson (2008) suggests that after Hurricane Katrina, community re-construction should focus on meaningful social support activities. In line with the above studies, participants indicated that social support networks supported them pass through ordeals. For example, some participant commented:

... residents in the neighborhood helped each others, worked together to pass through that period of time. People in the neighborhood showed their loving care for each other, listened to each other ... (TW 05).

Hakka people are close to their clan members. Right after the catastrophe, they put things together to make meals. In my neighborhood, we shared our food with the entire neighborhood (TW 06).

Tung Shih is a closed hillside township. Most of the local people are somehow related to each others. It's like what people often refer to as 'yam-vines.' They are connected somehow someway (TW 03).

Moreover, Participant FG 04 asserted, 'The mutual support group created new social support networks for its members. Group members walked beside each other and comforted each other'. Figley and McCubbin (1983) stress that survivors can gain numerous benefits by talking with other survivors and from discussing mutual concerns. As many disaster studies indicate, social support networks would facilitate survivors' disaster resilience or posttraumatic growth (e.g., Linley \& Joseph 2004). Rosenfeld et al. (2005, p. 341) even suggest that disaster workers check survivors' social support networks, and help them create one if they need. Rosenfeld et al. also claim that 'social support lets people know others see the world as they do'. In this study, the researchers found that for those who re-establish social support networks tend to be more resilient than those who do not mend theirs.

\section{Serving Others}

Serving others often makes people feel that they are needed and wanted. It brings people a sense of being useful to others. It also helps survivors to have a better understanding of the meaning and values of life. Through the process of serving others, it not only enhances the efficiency of assisting others, but also helps survivors themselves as well as others to grow. It leads survivors to gain new meaning and explanation for life after disasters (Al-Naser \& Sandman 2000; Farley 1998). Participant TW 01 affirmed, 'I found that caring for others helps me find hope in this world and makes me feel good about myself'.

\section{Experience of Natural Disasters}

The results showed that experience of natural disaster had direct but negative impacts on disaster resilience. Previous disaster experience could urge participants to start a hazard mitigation plan, hoping to reduce loss in the future disaster attacks, which could increase disaster 
resilience. However, the recent disaster experience often challenges residents' preparedness and disaster resilience.

\section{Post-disaster life events}

Post-disaster life events are found to have both positive and negative impacts on disaster resilience. They might include but not limit to the following events: deceased loved one's birthdays, marriage, job security, living rearrangements, mortgages of their collapsed house, and property divisions. Those events might break the current social support networks, and need to reestablish new ones.

\section{Conclusion}

Survivors of the 921 Earthquake in the Tung Shih areas were the target population for this study. Data were collected through in-depth interviews and focus groups. The purposive sampling strategies were used to select information-rich participants. A total of 15 interviewees and eight focus group members participated in this study. The purpose of this study was to explore factors facilitating disaster resilience. Qualitative data analysis software, ATLAS.ti 5.5, was used for cross-case analyses and content analyses. The emerged themes among the in-depth interviews and the focus group were compared. For those themes that have positive and direct impacts on disaster resilience are treated as protective factors of disaster resilience.

Protective factors at the personal-level include acceptance, preparedness, self-reliance, and spirituality. Protective factors at the community-level consist of Hakka spirit, resource availability, social support networks, and serving others. In addition, participants from the indepth interviews group recognised the roles of governmental agencies in disaster operational plans. The function and responsibility of the government should not be overlooked. However, participants from the focus groups paid special attention to the re-establishment of social support networks. They claim that for the long run, supports from family, clan members, neighbors, as well as friends are essential, even more important than materials or practical aids from outsiders.

A hillside township like Tung Shih, a closed community is naturally formed. It may be easier for its residents to control their resources and re-establish social support networks. In an industrial city, like Taichung, reconstructing social support networks may not be an easy task. Further research may be focused on comparisons between closed community and open community. Besides, in the future, researchers may well consider a mixed method design that uses quantitative and qualitative methods to confirm and cross-validate the findings.

\section{Acknowledgments}

Support for this work was provided by Grants NSC 962625-Z-040-001, NSC 97-2625-M-040 -001, and NSC
97- 2625-M-130-001 from the National Science Council, Taiwan.

\section{References}

Abramson, D., Stehling-Ariza, T., Garfield, R., \& Redlener, I. (2008). Prevalence and predictors of mental health distress post-Katrina: Findings from the Gulf Coast Child and Family Health Study. Disaster Medicine and Public Health Preparedness, 2(2), 77-86.

Al-Naser, F., \& Sandman, M. (2000). Evaluating resilience factors in the face of traumatic events in Kuwait. SQU Journal for Scientific Research, 2, 111-116.

Bandura, A. (1989). Human agency in social cognitive theory. American Psychologist, 44(9), 1175-1184.

Bankoff, G. (2004). The historical geography of disaster: 'vulnerability' and 'local knowledge' in western discourse. In G. Bankoff, G. Frerks, \& D. Hilhorst (Eds.), Mapping vulnerability: Disasters, development and people. (pp. 25-36). London: Earthscan.

Bankoff, G., Frerks, G. \& Hilhorst, D. (Eds.). (2004). Mapping vulnerability: Disasters, development and people. London: Earthscan.

Bellavita, C. (2008). Changing homeland security: What is homeland security? Homeland Security Affairs, 4(2), 1-30.

Benight, C. C., Ironson, G., Klebe, K., Carver, C. S., Wynings, C., Burnett, K., et al. (1999). Conservation of resources and coping self-efficacy predicting distress following a natural disaster: A causal model analysis where the environment meets the mind Anxiety, Stress, and Coping, 12, 107-126.

Cadell, S., Regehr, C. \& Hemsworth, D. (2003). Factors contributing to posttraumatic growth: A proposed structural equation model. American Journal of Orthopsychiatry, 73(3), 279-287.

Cannon, T. (2008). Vulnerability, 'innocent' disasters and the imperative of cultural understanding. Disaster Prevention and Management, 17(3), 350-357.

Cardona, O. D. (2003). The need for rethinking the concepts of vulnerability and risk from a holistic perspective: A necessary review and criticism for effective risk management. In G. Bankoff, G.. Frerks, \& Hilhorst, D. (Eds.), Mapping vulnerability: disasters, development and people. London: Earthscan.

Carpenter, M., Hodge, J. G., \& Pepe, R. P. (2008). Deploying and using volunteer health practitioners in response to emergencies: Proposed uniform state legislation provides liability protections and workers' compensation coverage. American Journal of Disaster Medicine, 3(1), 17-23.

Chou, H. C. (2009, July). The experience of developing Safe Taiwan Information System (SATIS) in Taiwan. 34th Annual Hazards Research and Applications Workshop, Natural Hazards Center at University of Colorado at Boulder, Broomfield, CO, USA.

Disaster Response Report (2008). Ministry of the Interior Department of Statistics, Taiwan. Retrieved December 28, 2008, from http://www.moi.gov.tw/stat/index.aspx

Dove, M. R. (2008). Perception of volcanic eruption as agent of change on Merapi volcano, Central Java. Journal of Volcanology and Geothermal Research, 172(3-4), 329-337. 
Farley, J. E. (1998). Down but not out: Earthquake awareness and preparedness trends in the St. Louis metropolitan area, 1990-1997. International Journal of Mass Emergencies and Disasters. 16(3), 303-319.

Figley, C. R., \& McCubbin, H. I. (Eds.). (1983). Stress and the family, 2: Coping with catastrophe. New York: Brunner/ Mazel.

Gutierrez, L., Zuniga, M. E., \& Lum, D. (Eds.). (2004). Education for multicultural social work practice: Critical viewpoints and future directions. Alexandria, VA: Council on Social Work Education.

Granot, H. (1995). Proposed scaling of the communal consequences of disaster [Research paper]. Disaster Prevention and Management, 4(3), 5-13.

International Federation of Red Cross and Red Crescent Societies (IFRC). (2002). World Disasters Report 2002: Focuses on reducing risk. Geneva: Author.

Jameson, M. (2002). Problem-focused coping: How to bounce back with strength you didn't know you had. Woman's Day Magazine. October, 67-70.

Jang, L. (2008). Natural disasters: Effects of cultural factors on resilience. North Charleston, SC: VDM Verlag Dr. Muller Aktiengesellschaft \& Co. KG and Licensors.

Jang, L. \& LaMendola. W. (2006). The Hakka spirit as a predictor of resilience. In D. Paton \& D. Johnston. Disaster resilience: An integrated approach. Springfield, IL: Charles C. Thomas.

Jang, L. \& LaMendola, W. (2007, Fall), Social work in natural disasters: The case of spirituality and posttraumatic growth, Advances in Social Work Journal, 8(2), 67-78.

Jordan, D. K. (n.d.). The traditional Chinese family and lineage. Retrieved June 14, 2004 from http://weber.ucsd.edu/ dkjordan/chin/hbfamilism-u.html

Karanci, N. A., Alkan, N., Aksit, B., Sucuoglu, H., \& Balta, E. (1999). Gender differences in psychological distress coping, social support and related variables following the 1995 Dinar (Turkey) earthquake. North American Journal of Psychology, 1(2), 189-204.

Lewis, J. (1999). Development in disaster-prone places: Studies of vulnerability. London: Intermediate Technology Publications.

Liao, Y. L. (1999). The earthquake disaster of the century. Feng Yuan, Taiwan: Taichung County Government. (In Chinese)

Lin, L. (2002). The statistic analysis of natural disasters in Taiwan and Fu-jian. Taipei, Taiwan: Department of Statistics, Ministry of the Interior. (In Chinese).

Linley, P. A., \& Joseph, S. (2004). Positive change following trauma and adversity: A review. Journal of Traumatic Stress, 17(1), 11-21.

Liverman, D. (1989). Vulnerability to global environmental change. Workshop on Understanding Global Environmental Change, Worcester, MA: Clark University.

Mileti, D. S. (1996). The character and form of effective natural hazard public information. Paper presented at the Pan Pacific Hazards '96 Conference, Vancouver, Canada

Mileti, D.S. (1999) Disaster by design: A reassessment of hazards in the United States. Washington DC: Joseph Henry Press,.
Miller, M., Paton, D., \& Johnston, D. (1999). Community vulnerability to volcanic hazard consequences. [Research paper]. Disaster Prevention and Management, 8(4), 255-260.

Mitchell, J. K. (1990). Human dimensions of environmental hazards: Complexity, disparity, and search for guidance. In A. Kirby (Ed.), Nothing to fear: Risks and hazards in American society (pp.131-175). Tucson, AZ: University of Arizona Press.

Nathanson, I. (2003). Spirituality and the life cycle. In T. Tirrito \& T. Cascio (Eds.), Religious organizations in community services: A social work perspective (pp. 63-77). New York: Springer

Nelson, L. P. (2008). A resiliency profile of Hurricane Katrina adolescents: A psychosocial study of disaster. Canadian Journal of School Psychology, 23(1), 57-69.

Norris, F. H., Byrne, C. M., \& Diaz, E. (2001, September). 50,000 disaster victims speak: An empirical review of the empirical literature, 1981-2001. The National Center for PTSD and the Center for Mental Health Services (SAMHSA).

Paton, D. (2000). Emergency planning: Integrating community development, community resilience, and hazard mitigation. Journal of the American Society of Professional Emergency Planners, 7, 109-118.

Paton, D. (2006). Disaster Resilience: Integrating individual, community, institutional and environmental perspectives. In D. Paton \& D. Johnston (Eds.), Disaster resilience: An integrated approach. Springfield, Ill.: Charles C. Thomas.

Paton, D. (2006b). Disaster resilience: Building capacity to coexist with natural hazards and their consequences. In D. Paton \& D. Johnston (Eds.), Disaster resilience: An integrated approach. Springfield, Ill.: Charles C. Thomas.

Paton, D., \& Johnston, D. (2001). Disasters and communities: Vulnerability, resilience and preparedness. Disaster Prevention and Management, 10(4), 270-277.

Paton, D., Violanti, J. M., \& Smith, L. M. (Eds.). (2003). Promoting capabilities to manage post-traumatic stress: Perspectives on resilience. Springfield, IL: Charles C Thomas Publisher, Ltd.

Paton, D., \& Jang, L. (in press). Disaster resilience: Exploring all-hazards and cross-cultural perspectives. In D. Miller \& J. Rivera (Eds.), Community disaster recovery and resiliency: Exploring global opportunities and challenges. Oxford: Taylor \& Francis.

Patton, M. Q. (1990). Qualitative evaluation and research methods (2nd ed.). Newbury Park, CA: Sage.

Rabin, C. L. (Ed.). (2005). Understanding gender and culture in the helping process: Practitioners' narratives from global perspectives. Belmont, CA: Thomson/Wadsworth.

Religion. (2004). A brief introduction to Taiwan. Retrieved May 27, 2005, from http://www.gio.gov.tw/taiwan-website/5gp/brief/info04_19.html

Rolf, J. E. (1999). Resilience: An interview with Norman Garmezy. In M. D. Glantz \& J. L. Johnson (Eds.), Resilience and development: Positive life adaptations (pp. 5-14). New York: Kluwer Academic/Plenum Publishers. 
Rosenfeld, L. B., Caye, J. S., Ayalon, O., \& Lahad, M. (2005). When their world falls apart: Helping families and children manage the effects of disasters. Washington, DC: NASW Press.

Saleebey, D. (Ed.). (2002). The strengths perspective in social work practice (3rd ed.). Boston, MA: Allyn \& Bacon.

The social aid to and placement of refugees in 921 big quake analysis. (n.d.). Retrieved May 26, 2005 from http://www. moi.gov.tw/stat/english/index.asp

Tung Shih Township Farmers Association (2008) Retrieved December 28, 2008 from http://www.tsfa.org.tw/
Wang, X., Gao, L., Shinfuku, N., Zhang, H., Zhao, C., \& Shen, Y. (2000, August). Longitudinal study of earthquake-related PTSD in a randomly selected community sample in north China. American Journal of Psychiatry, 157, 1260-1266.

Wisner, B. (1993). Disaster vulnerability: Scale, power, and daily Life. GeoJournal, 30(2), 127-140.

Yang, W. S. (2004). A census of the Hakka population in Taiwan. Taipei, Taiwan: Council for Hakka Affairs, Executive Yuan, R. O. C. [in Chinese]. 